\title{
Recursos públicos investidos na educação infantil: uma análise das consultorias internacionais
}

\author{
Dulce Mara Langhinotti Carpes \\ Ângela Mara de Barros Lara \\ Universidade Estadual de Maringá (Brasil)
}

\section{Resumo}

artigo tem por objetivo analisar como se viabilizaram os recursos públicos destinados à implementação da política nacional para educação infantil por intermédio de convênios firmados pelo Brasil com os organismos internacionais para contratação de consultorias no período de 2012 e 2013. No intuito de subsidiar os argumentos, foram consultadas as concepções dos organismos internacionais, Organização dos Estados Ibero-americanos e Organização das Nações Unidas para Educação, a Ciência e a Cultura. Analisaram-se os documentos do Ministério da Educação - Relatórios de Gestão do Ministério da Educação, referentes à Secretaria da Educação Básica e Coordenação Geral da Educação Infantil dos anos de (2012-2013). A construção do referencial e as análises foram desenvolvidas à luz do materialismo histórico-dialético. A análise dos dados caracteriza-se como qualitativa e se deu por meio da pesquisa documental e da análise de conteúdo. Dentre os resultados, constatou-se que os recursos públicos foram viabilizados na perspectiva de uma política focalizada, na lógica da redução de gastos.

Palavras-chave: Recursos públicos. Educação infantil. Consultorias. Organismos internacionais.

\section{Public resources invested in children education: an analysis of international consultancies}

\begin{abstract}
The purpose of this article is to analyze how were enablethe public resources destined to the implementation of the national policy for children education via the agreements signed by Brazil with the international organizations for the contracting of consultancies in the period of 2012 and 2013 . In order to subsidize the arguments, we have consulted the conceptions of international organizations, the Organization of Ibero-American States and the United Nations Organization for Education, Science and Culture. We have analyzed the documents of the Ministry of Education - Management Reports of the Ministry of Education, concerning the Secretary of Basic Education and General Coordination of Children Education for the years 2012 and 2013 . The construction of the referential and the analyzes were developed in the light of historical-dialectical materialism. The analysis of the data is characterized as qualitative and occurred through documentary research and content analysis. Among the results, we have verified that the public resources were made possible in the perspective of a focused policy, in the logic of cost reduction.

Keywords: Public resources. Children education. Consulting. International organizations.
\end{abstract}




\section{Recursos públicos investidos en la educación infantil: un análisis de las consultorías internacionales}

\section{Resumen}

El artículo tiene por objetivo analizar cómo se viabilizaron los recursos públicos destinados a la implementación de la política nacional para educación infantil por intermedio de convenios firmados por Brasil con los organismos internacionales para contratación de consultorías en el período de 2012 y 2013. Con el fin de subsidiar los argumentos, se han consultado las concepciones de los organismos internacionales, Organización de los Estados lberoamericanos y Organización de las Naciones Unidas para la Educación, la Ciencia y la Cultura. Se analizaron los documentos del Ministerio de Educación - Informes de Gestión del Ministerio de Educación, referentes a la Secretaría de Educación Básica y Coordinación General de la Educación Infantil de los años de 2012 y 2013 . La construcción del referencial y los análisis se desarrollaron a la luz del materialismo histórico-dialéctico. El análisis de los datos se caracteriza como cualitativa y se dio por medio de la investigación documental y del análisis de contenido. Entre los resultados, se constató que los recursos públicos fueron viabilizados en la perspectiva de una política enfocada, en la lógica de la reducción de gastos.

Palabras clave: Recursos públicos. Educación infantil. Consultorías. Organismos internacionales.

\section{Introdução}

O presente trabalho situa-se no âmbito das mudanças políticas e econômicas ocorridas no Brasil em fins do século XX e limiar do século XXI, as quais coincidiram com os novos delineamentos da conjuntura internacional. A partir desta perspectiva, procuramos empreender um debate sobre os recursos públicos, viabilizados no contexto da Política Nacional de Educação Infantil. $\bigcirc$ estudo contextualiza aspectos históricos decisivos para a educação brasileira após a promulgação da Constituição Federal de 1988, que instituiu o conceito de Estado de Direito, que se constituiu permeado por constantes disputas no cenário polííico e educacional.

Ao adentrar no estudo das políticas educacionais, especialmente na área de análises de políticas, é fundamental ter o conhecimento de que se tratam de decisões institucionais em que transitam diferentes interesses. Evangelista (2012) observa que os documentos oriundos do aparelho de Estado, de organizações multilaterais, de agências, de intelectuais orgânicos e não orgânicos, expressam não apenas diretrizes para a educação, mas articulam interesses, projetam políticas e produzem intervenções sociais. 
Alguns estudos' trazem a discussão a respeito das indicações da Organização dos Estados Ibero-americanos (OEI) e Organização das Nações Unidas para Educação, a Ciência e a Cultura (UNESCO) voltadas para a educação infantil, bem como tratam dos principais documentos produzidos pelos referidos organismos em relação às concepções e à lógica que os sustentam. As autoras partem da ideia da existência de uma relação entre mundo globalizado, organismos internacionais e governos locais. Tal pressuposto advém da presença desses organismos, bem como seus princípios e estratégias nos projetos educacionais dos países latino-americanos, nos quais a educação infantil está enquadrada na estratégia do combate à pobreza que se efetiva por meio de políticas focalizadas para as crianças e famílias em situação vulnerável.

A presença dos organismos internaciona is como a OEI e UNESCO nas políticas educacionais brasileiras são verificados nos convênios firmados entre esses organismos junto ao Ministério da Educação (MEC) nos anos de 2012 e 2013.

presente estudo busca avançar no campo científico desvelando a influência exercida pelos organismos internacionais, bem como a compreensão dos rumos tomados pela educação no Brasil após a década de 1990, especificamente, no que se refere à educação infantil. $\bigcirc$ estudo teve como objetivo analisar como se viabilizaram os recursos públicos destinados à implementação da política nacional para educação infantil, por intermédio de convênios firmados pelo Brasil com os organismos internacionais para contratação de consultorias no período de 2012 e 2013 . A análise do papel das consultorias $^{2}$ fez-se necessário na medida em que contribuíram no processo de difusão das Diretrizes Curriculares Nacionais para a Educação Infantil (DCNEI). Nesse sentido o estudo traz elementos que podem contribuir para o entendimento da relação existente entre as políticas públicas para educação infantil no Brasil com a dinâmica da reestruturação do capital e suas determinações.

No que se refere à contribuição social, a pesquisa propõe levar aos profissionais da área a compreensão do universo em que são geradas e construídas as políticas educacionais. A pesquisa colabora para uma análise crítica dos propósitos contidos nas políticas educacionais destinadas às crianças de 0 a 5 anos, desvelando disputas e interesses, bem como as estratégias utilizadas nos discursos contidos nos documentos, de modo que osprofessores possam atuar de forma mais crítica no processo educacional. 
Para compreender o movimento que levou a contratação de consultorias via convênios do Brasil com organismos externos, foram verificados e analisados os Relatórios de Gestão do Ministério da Educação (MEC), referentes à Secretaria de Educação Básica (SEB), Coordenação da Educação Infantil (COEDI), dos anos de 2012 e 2013, o que caracteriza a pesquisa como documental. A escolha do referido período para análise se deve ao fato que há um maior número de dados contidos nos anos de referência. Foram consultadas as concepções e linhas de atuação da UNESCO e OEl para identificar em que medida suas orientações são seguidas pelo Brasil.

○ referencial e as análises foram desenvolvidos com base na perspectiva teórico-metodológica do materialismo histórico-dialético. Entende-se que a referida teoria é capaz de possibilitar uma interpretação de mundo mais ampliada. Refutam-se as proposições positivistas e pós-modernas por entender que o particular não é capaz de explicar o movimento do todo, que o mais simples não pode explicar o mais complexo. As categorias tomadas do método dialético foram totalidade, contradição e mediação, as quais possibilitam contribuir com a análise das relações que se manifestam na prática, bem como, na compreensão dos mecanismos que perpassam a organização capitalista.

No procedimento de análise de conteúdo (BARDIN, 1977), foram definidas as categorias de análise nos Relatórios de Gestão: "educação infantil" e "ações". A abordagem da análise dos dados caracteriza-se predominantemente como qualitativa.

\section{O universo das políticas educacionais brasileiras}

O último terço do século XX foi marcado por transformações que acentuaram a essência do modo de produção capitalista (GORENDER, 1997). Reconheceu-se que, para sua manutenção e produtividade após o fim da Guerra Fria, o sistema capitalista dependia da existência de um mundo seguro e sustentável, configurado num fenômeno políitico-econômico de grande amplitude, conduzido pelo lucro. Nesse sentido, Fontes (2010) ressalta que são inúmeras as práticas de difusão formuladas pelos países dominantes, explicitadas no desejo da hegemonia do capital. Segundo José PauloNetto (2006), como garantia para a máxima obtenção de lucros, foi necessário refuncionalizar o Estado, que se tornou instrumento de viabilização dessa 
Dulce Mara Langhinotti Carpes | Ângela Mara de Barros Lara

tarefa. Nessa linha de raciocínio, para o Estado atuar em consonância com as novas necessidades do capital precisaria superar suas estruturas arcaicas e buscar adequação aos novos padrões, conforme postulou o Consenso de Washington ${ }^{3}$. Uma das ações que apontam nessa direção foi a realização da Conferência Mundial sobre Educação para Todos, realizada em Jomtien, em 1990 (UNESCO, 1990).

A referida conferência, da qual resultou a Declaração Mundial sobre Educação para Todos, foi financiada pela UNESCO, Fundo das Nações Unidas para a Infância (UNICEF), Programa das Nações Unidas para o Desenvolvimento (PNUD) e Banco Mundial (BM), organismos que constituem o Sistema das Nações Unidas. Na conferência, inaugurou-se em nível mundial um macroprojeto para a década de 1990, centrado na ideia da Satisfação das Necessidades Básicas de Aprendizagem. Entretanto, ressaltava-se que, para as necessidades básicas de aprendizagem fossem atendidas, seria essencial mobilizar atuais e novos recursos financeiros, recursos humanos, públicos, privados ou voluntários (UNESCO, 1990). No mesmo ano da conferência, o Banco Mundial publicou o relatório intitulado "A Pobreza", no qual sugere alternativas e encaminhamentos a serem adotados pelos países que se enquadravam em tal situação, no sentido de reduzirem o número de pessoas que viviam na linha da miséria. Observa-se que as recomendações partem de uma estratégia composta por dois elementos.

Um deles é a utilização produtiva do bem que os pobres mais dispõem - o trabalho [...]. O outro elemento é a prestação de serviços sociais básicos aos pobres - em especial atendimento médico, planejamento familiar, nutrição e educação primária (BANCO MUNDIAL, 1990, p. 3).

documento do Banco Mundial aponta as estratégias que se valem da educação como importante instrumento no combate à pobreza. Na concepção do banco, a capacidade produtiva das pessoas pobres deveria ser otimizada via oferta da educação básica. Tal entendimento associa-se à Teoria do Capital Humano, que, conforme Frigotto (2015), sedimenta um reducionismo da concepção de ser humano a uma mercadoria. $\bigcirc$ trabalho como atividade vital que produz o ser humano é entendido como a venda da força de trabalho humana (emprego). A noção de educação, de um direto social e 
subjetivo, é absorvida por uma concepção mercantil de formação humana. Nessa discussão, Leher escreve que a educação tem cumprido

[...] a importante função ideológica de operar as contradições advindas da exclusão estrutural dos países periféricos que se aprofunda de modo inédito. O Banco Mundial inscreve a educação nas políticas de aliviamento da pobreza como ideologia capaz de evitar a 'explosão' dos países e das regiões periféricas e de prover o neoliberalismo de um porvir em que exista a possibilidade de algum tipo de inclusão social ('†odo aquele que se qualificar poderá disputar, com chance, um emprego'), para isto, a coloca no topo de seu programa de tutela nas regiões periféricas (LEHER, 1998, p. 9).

Por meio de acordos multilaterais, os países periféricos, bem como suas burguesias, consentem e cooperam no processo de sociabilidade do sistema capitalista. Conforme Fontes (2010), as burguesias mesmo que subalternas necessitam, continuamente, expandir formas de encapsulamento dos trabalhadores ao mesmo tempo em que expandem suas fontes de extração de mais-valia.

Em conformidade com essa lógica, foram criados na América Latina ramificações dos organismos internacionais para o desenvolvimento dos sistemas públicos de ensino, por meio de formulações que extrapolam a esfera pública. Percebe-se um interesse explícito em impedira exclusividade do Estado na oferta da Educação enquanto direito da sociedade, suscitando disputas no campo político e econômico em países nos quais seus documentos preveem o estado de direito, como é o caso do Brasil.

Foram desenvolvidos projetos em âmbitos regionais para América Latina e Caribe de modo a alcançar os objetivos educacionais. Des-aca-se como atuante na região o Projeto Regional de Educação para a América Latina e Caribe (PRELAC), sob a jurisdição da Unesco e a Agenda Ibero-Americana para a Infância e a Adolescência (AllA), sob coordenação da Organização dos Estados Ibero-Americanos (OEI).

No contexto brasileiro, em face à grave crise financeira enfrentada pelo país no final da década de 1980, o governo brasileiro optou por aderir ao ideário neoliberal recém-consolidado no Consenso de Washington, assentado no tripé desregulação, privatização e liberalização dos mercados (SILVA, 20 14). Inicialmente, tais pressupostos foram assumidos pelo governo de 
Fernando Collor de Melo (PEDREIRA, 2006). Em 1995, o governo de Fernando Henrique Cardoso, em atendimento às recomendações do Banco Mundial, criou o Ministério da Administração Federal e da Reforma do Estado (MARE)4, Ao reformar o Estado, o governo brasileiro adotou princípios da administração gerencial na lógica da teoria da New Public Management ${ }^{5}$, ou nova gestão pública, na qual a hipótese principal é que mais mercado no setor público contribuiria para uma maior eficiência de custos para os governos (MOREIRA, 2012 ). Tal entendimento apoiava-se na ideia que é o Estado que se encontrava em crise, não o sistema capitalista. Conceituações e processos operacionais utilizados no mundo dos negócios também passaram a orientar a gestão dos recursos destinados às políticas educacionais.

\section{Gestão para Educação Infantil: perspectivas dos organismos internacionais OEI e UNESCO}

De modo geral, nos documentos dos organismos internacionais atuantes na América Latina são explicitadas estratégias comuns, com prioridade para educação e saúde das mulheres. A indicação de programas de atendimento de baixo custo para disciplinar as famílias, a educação infantil, entendida como medida compensatória que deve privilegiar crianças e famílias em situação de risco (CAMPOS; CAMPOS, 2008). Tais orientações advém das origens da OEI e UNESCO.

Criada em 1949, a Organização dos Estados Ibero-americanos ${ }^{6}$ para a Educação, a Ciência e a Cultura (OEI) constitui-se em um organismo internacional de caráter governamental para a cooperação entre os países e povos ibero-americanos no campo da educação, da ciência, da tecnologia e da cultura no contexto do desenvolvimento da democracia. Com sede em Madri, sua atuação mais direta nos países da América Latina se deu a partir da I Conferência lbero-americana de Chefes de Estado e de Governo, ocorrida no México em 1991. Essa conferência promoveu e convocou as Conferências de Ministros de Educação dos países membros. A OEl é formada por países ibero-americanos, com escritórios em boa parte de seus países membros.

No que se refere aos objetivos educacionais, embora a OEI não se refira diretamente às metas estabelecidas nas Conferências Mundiais de Educação de Jomtien e Dakar, seus documentos mencionam os mesmos 
objetivos e metas elaboradas no ano 2000, pela Organização das Nações Unidas $(\mathrm{ONU})^{7}$. O documento "Fuentes de financiamento adicionales para lograr el compromiso com las metas educativas 2021 l" (OIE, 2008) denota o alinhamento deste organismo com a forma de atuação dos organismos vinculada à ONU. A educação inicial (no Brasil denominada educação infantil) foi prescrita na X Conferência lbero-americana de Educação como um dos fatores estratégicos para garantir a equidade, diminuir os efeitos da pobreza e promover o apoio ao desenvolvimento econômico e à competitividade dos países membros (OEI, 2000). Reduzir a pobreza para maximizar a capacidade do trabalhador, o que não significa acabar com a pobreza, uma vez que o que prevalece é a ideia de manutenção, não de transformação, na sociedade de classe.

A OEl objetiva, sobretudo, cooperar com os Ministérios da Educação de modo a colaborar na governabilidade das instituições públicas, no que tange o desenvolvimento da formação de professores, bem como a introdução de um sistema de indicadores de desempenho e avaliação (OEI, 2000). A organização entende ser necessário promover acordos políticos e sociais para fortalecer a participação da sociedade no desenvolvimento da educação. Ao 8 promovera cooperação técnica na esfera dos planos educacionais, suas diretrizes influenciam os sistemas educativos dos países membros.

A Agenda Ibero-americana para a Infância e a Adolescência (AllA) foi criada para atuar, junto à primeira infância, na lógica de potencializar o desenvolvimento da criança a partir da instituição família em âmbito regional e local (OEI, 2001). A OEl promove o desenvolvimento de estratégias que orientem os pais a criarem seus filhos, capacitando-os no cumprimento de tal tarefa. A organização não aponta o Estado como único responsável pela gestão da educação infantil de qualidade.

A Organização Educacional, Científica e Cultural das Nações Unidas (UNESCO) foi criada pela Assembleia Geral das Nações Unidas e entrou em vigor em 1946. De acordo com documentos orientadores dessa organização, referentes à educação, seu enfoque central está no aprimoramento da educação mundial por meio de assessoramento técnico. A agência define-se como incentivadora e disseminadora de propostas educacionais inovadoras para desafios encontrados pelos países signatários. Constitui um dos organismos mais importantes do sistema das Nações Unidas, que congrega 190 Estados 
membros, o que significa que possui uma atuação, praticamente, no mundo inteiro.

No documento elaborado pela UNESCO e pela Comissão Econômica para a América Latina e o Caribe (CEPAL, 2005), intitulado Investir melhor para investir mais: financiamento e gestão da educação na América Latina e no Caribe, a educação é citada como mola do desenvolvimento econômico. Com o propósito de atingir melhores índices, a Unesco orienta países da América latina e Caribe a promoverem mudanças no planejamento dos seus sistemas de ensino, centrando na priorização e reorientação dos financiamentos, nas funções do Estado e introdução de sistema de monitoramento. Conforme Silva (2014), esse processo tem propiciado em nível mundial a busca por uma padronização, pautada em indicadores e metas quantificáveis, que devem permitir aos organismos internacionais o monitoramento dos sistemas educacionais no âmbito dos governos locais.

Como forma de atingir tais propósitos, foi elaborado pela UNESCO - Projeto Regional de Educação para a América Latina e Caribe (PRELAC). O PRELAC surge para atender ao pedido dos ministros da região com o objetivo de estimular mudanças substantivas nas políticas públicas. $\bigcirc$ projeto objetiva o cumprimento do Plano de Ação da Conferência Mundial no âmbito dos governos locais, e parte do princípio que a educação é mecanismo para a promoção da equidade social, ademais, preconiza a educação das crianças de zero a três anos como tarefa da família.

Os estudos Campos e Campos (2008) partem do pressuposto que uma agenda globalmente estruturada tem orientado as políitcas para a Educação Infantil nos países da região da América Latina e Caribe. Desse pressuposto, as autoras extraem que nos documentos publicados pela OEl e UNESCO são encontradas orientações voltadas ao combate à pobreza, informam que as políticas focalizadas e compensatórias aparecem como a principal indicação nos projetos destinados às crianças de 0 a 3 anos de idade.

Percebe-se que ao assinar acordos com os organismos internacionais, os países, de forma consentida, abrem mão de planejarem suas próprias estratégias para a resolução dos problemas, ao passo que coadunam na execução do projeto internacional.

Estudos deleher (1998); Frigotto e Ciavatta (2003); Neves (2005); Evangelista e Shiroma (2006); Silva (2014) e Libâneo (2016) têm abordado a 
implicação da internacionalização das políticas educacionais nos documentos dos planos e diretrizes que orientam o sistema de ensino brasileiro. No mesmo sentido, Zanardini (2006); Libâneo (201 2); Miranda e Santos (2012); Zanardini (2014) e Fernandes (2015) têm analisado o impacto das políticas educacionais nos objetivos e nas formas de gestão da escola pública. Com base nos referidos estudos, identifica-se que as ações dos organismos internacionais se relacionam comumente à cooperação técnica e financeira à países com dificuldades econômicas. $\bigcirc$ apoio se dá por meio de empréstimos para realização de programas relacionados, basicamente, à saúde, educação e saneamento (LIBÂNEO, 2016).

É importante ressaltar que tanto a OEI como a UNESCO possuem uma forma de gestão semelhante, o que significa que as estratégias para a condução das políticas educacionais para a infância seguem o mesmo direcionamento, não importando, necessariamente, que a origem do organismo seja a Europa ou as Américas.

Nos anos de 2012 e 2013, o Brasil, com o intuito de universalizar a educação infantil até o ano de 2016, firmou acordo de cooperação técnica com a OEl e com a UNESCO por meio da contratação de consultoria,

10 dando anuência às orientações dos programas educacionais dos referidos organismos.

\section{Cooperação técnica por meio das consultorias dos organismos internacionais: gastos públicos ou investimento educacional?}

Nesta seção são analisados, especificamente, os recursos desti-nados pelo governo na contratação de consultorias, via convênio com a OEl e UNESCO, nos anos 2012 e 2013 . A partir da análise dos relatórios de gestão orçamentária do MEC, relativos à Secretaria de Educação Básica (SEB), buscou-se construir argumentos para uma análise das perspectivas expostas e intrínsecas no processo de viabilização de recursos públicos no contexto da Política Nacional de Educação Infantil.

produto final das consultorias era gerar propostas de organização das políticas públicas e formas de atuação do MEC na área da educação infantil. $\bigcirc$ montante de recursos financeiros destinados para ação das consultorias nos anos de 2012 e 2013 totalizou R\$ 1.200.000,00 (um milhão e 
duzentos mil reais). Durante os anos de 2012 e 2013, as consultorias contratadas propuseram ações no intuito de legitimar as políticas públicas destinadas à educação infantil, propostas pelo MEC/COEDI. Inicialmente, apresenta-se uma análise das informações contidas no relatório de 2012 e, na sequência, as evidenciações de 2013.

O relatório do MEC de 2012 continha 73\% das ações das consultorias que priorizaram a proposição de processos de planejamento técnico-pedagógico e de gestão/avaliação da política de educação infantil nos municípios participantes do Proinfância ${ }^{8}$ nos estados. As ações se referem à implantação e aprimoramento das propostas pedagógicas em congruência com as Diretrizes Curriculares Nacionais para a Educação Infantil (DCNEI). Já o restante das ações das consultorias (27\%), focou em aspectos da saúde e da assistência social. Verificou-se que os esforços eram voltados aos municípios participantes do Proinfância.

Em 2012, foram contratadas 11 consultorias, que movimentaram recursos na ordem de $\mathrm{R} \$ 753.000,00$ (setecentos e cinquenta e três mil reais). As consultorias se propuseram a implantar ações voltadas a atender à Política Nacional de Educação Infantil. Um conjunto de 8 consultorias atuaram em processos de planejamento técnico-pedagógico e de gestão/avaliação da política de educação infantil nos municípios participantes do Proinfância, para a implantação e aprimoramento das propostas pedagógicas em congruência com as DCNEI. Nesse processo, foi investido um montante de R \$590.000,00 (quinhentos e noventa mil reais). As outras três consultorias se ativeram em outras áreas de atuação, como identificaras boas práticas voltadas para a saúde e bem-estar da criança, assim como propor subsídios para a atualização de dados ao programa saúde na escola e reformulação da Caderneta de Saúde da Criança, com foco nos aspectos educacionais. Tal instrumento contemplaria informações referentes às ações das políticas de saúde, assistência social e educação infantil.

Um terceiro projeto de consultoria previa mecanismos de avaliação da educação infantil, a partir de experiências nacionais e internacionais. Os valores investidos nas três consultorias foram de R\$163.000,00 (cento e sessenta e três mil reais). Os recursos investidos foram subsidiados a partir do convênio entre o governo brasileiro e a OEl. $\bigcirc$ quadro 1 apresenta, separadamente, as consultorias, sua abrangência de atuação e recursos destinados. 


\section{Quadro 1}

\section{Mapa dos estados atendidos pelas consultorias do MEC/OEI}

\begin{tabular}{|c|c|c|c|c|}
\hline $\begin{array}{c}\text { Nome do } \\
\text { consultor }\end{array}$ & $\begin{array}{l}\text { Organismo } \\
\text { Internacional }\end{array}$ & Estados & Recurso & Objeto do contrato \\
\hline $\begin{array}{l}\text { Ana Lucia Peixoto } \\
\text { de Brito }\end{array}$ & OEI & $\begin{array}{l}\text { AL, AM, CE, MA, } \\
\text { PA, PB, PR, PE, PI, } \\
\text { SE, RJ e RN } \\
\text { - Atuou nos } \\
\text { Estados do AM e } \\
\text { PA. } \\
\end{array}$ & $90.000,00$ & \multirow{7}{*}{$\begin{array}{l}\text { Consultoria especializada } \\
\text { para propor processos de } \\
\text { planejamen-to técnico-pedagó- } \\
\text { gico e de ges-tão/avaliação } \\
\text { da política de educação infan- } \\
\text { til nos municípios participantes } \\
\text { do Proinfância, com vistas ao } \\
\text { aprimoramento das pro-postas } \\
\text { pedagógicas em con-gruência } \\
\text { com as Diretrizes Curricu-lares } \\
\text { Nacionais para a Educação } \\
\text { Infantil-DCNEl. }\end{array}$} \\
\hline \begin{tabular}{|l|} 
Maria de Fátima \\
Simas Malheiro
\end{tabular} & OEI & $\begin{array}{l}\text { AL, AM, CE, MA, } \\
\text { PA, PB, PR, PE, PI, } \\
\text { SE, RJ e RN } \\
- \text { Atuou nos } \\
\text { Estados do RJ e } \\
\text { RN. }\end{array}$ & $90.000,00$ & \\
\hline $\begin{array}{l}\text { D a n i e I | e } \\
\text { Marques Vieira }\end{array}$ & OEI & $\begin{array}{l}\text { AL, AM, CE, MA, } \\
\text { PA, PB, PR, PE, PI, } \\
\text { SE, RJ e RN } \\
\text { - Atuou no Estado } \\
\text { do PR. }\end{array}$ & $90.000,00$ & \\
\hline $\begin{array}{l}\text { Maria Geisa de } \\
\text { Andrade }\end{array}$ & OEI & $\begin{array}{l}\text { AL, AM, CE, MA, } \\
\text { PA, PB, PR, PE, PI, } \\
\text { SE, RJ e RN } \\
\text {-Atuou nos Estados } \\
\text { do AL e PE. } \\
\end{array}$ & $90.000,00$ & \\
\hline $\begin{array}{l}\text { Maria de Jesus } \\
\text { Araújo Ribeiro }\end{array}$ & OEI & $\begin{array}{l}\text { AL, AM, CE, MA, } \\
\text { PA, PB, PR, PE, PI, } \\
\text { SE, RJ e RN } \\
\text { - Atuou no Estado } \\
\text { do CE. }\end{array}$ & $90.000,00$ & \\
\hline $\begin{array}{l}\text { Sônia Maria de } \\
\text { Melo Barbosa }\end{array}$ & OEl & $\begin{array}{l}\mathrm{AL}, \mathrm{AM}, \mathrm{CE}, \mathrm{MA}, \\
\mathrm{PA}, \mathrm{PB}, \mathrm{PR}, \mathrm{PE}, \mathrm{PI}, \\
\left.\mathrm{SE}, \mathrm{RJ} \text { e RN. } \text { ( }^{*}\right)\end{array}$ & $90.000,00$ & \\
\hline $\begin{array}{l}\text { Regina Lúcia } \\
\text { Couto de Melo }\end{array}$ & OEl & $\begin{array}{l}\text { AL, AM, CE, MA, } \\
\text { PA, PB, PR, PE, PI, } \\
\text { SE, RJ e RN } \\
\text { - Atuou no Estado } \\
\text { do PR. }\end{array}$ & $29.000,00$ & \\
\hline
\end{tabular}




\section{Quadro 1}

\section{Mapa dos estados atendidos pelas consultorias do MEC/OEI (Continuação)}

\begin{tabular}{|c|c|c|c|c|}
\hline $\begin{array}{c}\text { Nome } \\
\text { consultor }\end{array}$ do & $\begin{array}{c}\text { Orga n i s mo } \\
\text { Internacional }\end{array}$ & Estados & Recurso & Objeto do contrato \\
\hline $\begin{array}{l}\text { Zilma de Moraes } \\
\text { Ramos de Oliveira }\end{array}$ & $\mathrm{OEI}$ & $\left({ }^{*}\right)$ & $23.000,00$ & $\begin{array}{l}\text { Subsidiar o processo de reformu- } \\
\text { lação da Caderneta de Saúde da } \\
\text { Criança, enfocando os aspectos } \\
\text { educacionais. }\end{array}$ \\
\hline $\begin{array}{l}\text { Ângela Maria } \\
\text { Rabelo ferreira } \\
\text { Barreto }\end{array}$ & $\mathrm{OEI}$ & $\begin{array}{l}\mathrm{AL}, \quad \mathrm{AM}, \\
\mathrm{CE}, \quad \mathrm{MA}, \\
\mathrm{PA}, \mathrm{PB}, \mathrm{PR}, \\
\mathrm{PE}, \mathrm{PI}, \mathrm{SE}, \\
\mathrm{RJ} \text { e } \mathrm{RN} . \\
\left(^{*}\right)\end{array}$ & $21.000,00$ & $\begin{array}{l}\text { Propor processos de planejamento } \\
\text { técnico-pedagógico e de gestão/ } \\
\text { avaliação da polí-tica de educação } \\
\text { infantil nos municípios participantes } \\
\text { do Proinfância, com vistas ao aprimo- } \\
\text { ramento das propostas pedagógicas } \\
\text { em congruência com as Diretrizes } \\
\text { Curriculares Nacionais para a } \\
\text { Educação Infantil - DCNEl. }\end{array}$ \\
\hline $\begin{array}{l}\text { Sandra Maria } \\
\text { ZakiaLian Sousa }\end{array}$ & $\mathrm{OEI}$ & $(*)$ & $96.000,00$ & $\begin{array}{l}\text { Elaborar proposta de mecanismos } \\
\text { sobre avaliação da educação infan- } \\
\text { til a partir de práticas e experiências } \\
\text { nacionais ou internacionais, em cur- } \\
\text { so, de modo a subsidiar o processo } \\
\text { de inclusão da Educação Infantil no } \\
\text { Sistema Nacional de Avaliação da } \\
\text { Educação Básica. }\end{array}$ \\
\hline $\begin{array}{l}\text { Damaris Gomes } \\
\text { Maranhão }\end{array}$ & OEl & $(*)$ & $44.000,00$ & $\begin{array}{l}\text { Identificar as boas práticas voltadas } \\
\text { para a saúde e bem-estar da criança, } \\
\text { assim como propor subsídios para } \\
\text { a atualização da matriz lógica das } \\
\text { ações do programa saúde na escola, } \\
\text { contemplando componente específi- } \\
\text { co para a educação infantil. }\end{array}$ \\
\hline TOTAL & - & & $753.000,00$ & \\
\hline
\end{tabular}

${ }^{*}$ ) Não consta o local em que prestou consultoria.

Fonte: Brasil (2013).

Por meio dos dados e números observados (Quadro 1), é possível perceber que a maioria das consultorias esteve centrada no processo de gestão e acompanhamento das políticas de educação infantil assim como na efetivação de ações voltadas para o planejamento técnico-pedagógico. Entretanto, a preocupação deveria ir além de uma política educacional voltada para aspectos 
operacionais e de assistência e voltar-se para as concepções pedagógicas da formação da criança pequena, enquanto direito constitucional. No que se refere ao amparo legal, o artigo 205 da Constituição Federal (CF) de 1988 afirma que a educação é direito de todos e dever do Estado e da família, que deve ser promovida e incentivada com a colaboração da sociedade, visando ao pleno desenvolvimento da pessoa, seu preparo para o exercício da cidadania e sua qualificação para o trabalho. Seu artigo 208 trata do dever do Estado com a educação, mediante a garantia de atendimento ao educando, em todas as etapas da educação básica, por meio de programas suplementares de material didático-escolar, transporte, alimentação e assistência à saúde (BRASIL, 1988). O artigo 29 da Lei de Diretrizes e Bases da educação Nacional (LDB), Lei n 9.394/96, que regulamenta a educação no Brasil, define o desenvolvimento integral da criança até seis anos de idade em seus aspectos físico, psicológico, intelectual e social, completando a ação da família e da comunidade (BRASIL, 1996).

Outro aspecto necessário tratar diz respeito às consultorias voltadas a operacionalizar a coleta de dados relativos às políticas de saúde e de assistência social. A Constituição Federal (CF) de 1988 e a Lei de Diretrizes e

14 Bases da educação Nacional (LDB) de 1996 avançaram ao retirar a educação infantil do Ministério do Desenvolvimento Social (MDS), transferindo-a para o Ministério da Educação (MEC) com o objetivo de garantir a escolarização da criança pequena. Nesse sentido, é necessária uma atenção para a proposição das referidas consultorias, para que não haja um retrocesso. Outra constatação refere-se à abrangência geográfica de atuação das consultorias, cuja presença foi predominante na região nordeste.

No ano de 2013,72\% das consultorias se centraram nas mesmas prioridades de 2012, já 28\% atuaram no diagnóstico das ações do MEC destinadas à formação de profissionais na gestão compartilhada e estudos de viabilidade para implantação de infraestrutura física e virtual. De forma geral, as consultorias contratadas objetivaram a disseminação das DCNEl.

No ano de 2013, foram contratadas 14 consultorias que se propu-seram trabalhar nos processos de planejamento técnico-pedagógico e de gestão/avaliação da política de educação infantil nos municípios participantes do Proinfância para dar continuidade à implantação e ao aprimoramento das propostas pedagógicas em consonância com as DCNEI. $\bigcirc$ quadro 2 
apresenta, separadamente, as consultorias, sua abrangência de atuação e recursos destinados.

\section{Quadro 2}

Mapa dos Estados atendidos pelas consultorias (BRASIL, 2014)

\begin{tabular}{|c|c|c|c|c|}
\hline $\begin{array}{c}\text { Nome } \\
\text { consultor }\end{array}$ & $\begin{array}{l}\text { Organis mo } \\
\text { Internacional }\end{array}$ & Estados & Recurso & Objeto do contrato \\
\hline $\begin{array}{l}\text { Ângela Maria } \\
\text { Rabelo Ferreira } \\
\text { Barreto }\end{array}$ & OEl & $(*)$ & $23.000,00$ & $\begin{array}{l}\text { Realização de estudo sobre as ações } \\
\text { do Ministério da Educação destina- } \\
\text { das à formação dos profissionais } \\
\text { que atuam na educação infantil, com } \\
\text { ênfase na análise da sistemática de } \\
\text { gestão compartilhada dessas ações, } \\
\text { envolvendo instâncias do MEC, das } \\
\text { agências formadoras e dos sistemas } \\
\text { de ensino. }\end{array}$ \\
\hline $\begin{array}{l}\text { Claudia Miranda } \\
\text { Martins }\end{array}$ & OEl & $\begin{array}{l}A C, \quad A M, \\
A L, \quad T O, \\
R R, \quad R N, \\
P B, P E, S E, \\
R J\end{array}$ & $31.000,00$ & $\begin{array}{l}\text { Consultoria especializada para } \\
\text { propor processos de planejamento } \\
\text { técnico-pedagógico e de gestão/ } \\
\text { avaliação da política de educação } \\
\text { infantil nos municípios participantes } \\
\text { do Proinfância, com vistas ao aprimo- } \\
\text { ramento das propostas pedagógicas } \\
\text { em congruência com as Diretrizes } \\
\text { Curriculares Nacionais para a } \\
\text { Educacãa Infantil - DCNEl. }\end{array}$ \\
\hline $\begin{array}{l}\text { Edna Oliveira Da } \\
\text { Paz }\end{array}$ & OEl & $\begin{array}{l}A C, \quad A M, \\
A L, \quad T O, \\
R R, \quad R N, \\
P B, P E, S E, \\
R J\end{array}$ & $31.000,00$ & \\
\hline $\begin{array}{l}\text { ElisabetRistow } \\
\text { Nascimento }\end{array}$ & OEl & AM, RN & 00,00 & \\
\hline
\end{tabular}




\section{Quadro 2}

\section{Mapa dos Estados atendidos pelas consultorias (BRASIL, 2014) (Continuação)}

\begin{tabular}{|c|c|c|c|c|}
\hline $\begin{array}{c}\text { Nome } \\
\text { consultor }\end{array}$ & $\begin{array}{l}\text { Organis mo } \\
\text { Internacional }\end{array}$ & Estados & Recurso & Objeto do contrato \\
\hline $\begin{array}{l}\text { Maria de Fatima } \\
\text { Simas Malheiro }\end{array}$ & OEl & 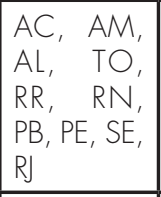 & $31.000,00$ & \multirow{2}{*}{$\begin{array}{l}\text { Consultoria especializada para } \\
\text { propor processos de planejamento } \\
\text { técnico-pedagógico e de gestão/ } \\
\text { avaliação da política de educação } \\
\text { infantil nos municípios participantes } \\
\text { do Proinfância, com vistas ao aprimo- } \\
\text { ramento das propostas pedagógicas } \\
\text { em congruência com as Diretrizes } \\
\text { Curriculares Nacionais para a } \\
\text { Educação Infantil - DCNEl. }\end{array}$} \\
\hline $\begin{array}{l}\text { Patricia Gomes de } \\
\text { Siqueira }\end{array}$ & OEI & $\begin{array}{l}A C, \quad A M, \\
A L, \quad T O, \\
R R, \quad R N_{,} \\
P B, P E, \quad S E_{,} \\
R J\end{array}$ & $31.000,00$ & \\
\hline $\begin{array}{l}\text { Claudia Maria da } \\
\text { Cruz }\end{array}$ & UNESCO & $\begin{array}{l}\text { GO, } E S, \\
C E, \quad M A, \\
P I, P A, A P, \\
M S, S C .\end{array}$ & $60.000,00$ & $\begin{array}{l}\text { Elaboração de estudo subsidiários } \\
\text { ao projeto de avaliação da implanta- } \\
\text { ção e da utilização pedagógica do } \\
\text { Programa Nacional do Livro Didático } \\
\text { (PNLD) nos sistemas de ensino. }\end{array}$ \\
\hline $\begin{array}{l}\text { Daniele Marques } \\
\text { Vieira }\end{array}$ & UNESCO & $\begin{array}{l}\text { RS, } \quad M T, \\
R O, P A, P I, \\
M A, B A \text { e } \\
\text { RJ. }\end{array}$ & $25.000,00$ & $\begin{array}{l}\text { Desenvolver estudo de viabilidades } \\
\text { para a implementação de espaços } \\
\text { virtuais para possibilitar a troca de } \\
\text { boas práticas entre as unidades do } \\
\text { Proinfância. }\end{array}$ \\
\hline $\begin{array}{l}\text { Fúlvia Maria } \\
\text { de Barros Mott } \\
\text { Rosemberg }\end{array}$ & UNESCO & $(*)$ & $32.000,00$ & $\begin{array}{l}\text { Propor metodologia de monitora- } \\
\text { mento da implantação da matrícula } \\
\text { obrigatória a partir dos } 4 \text { anos de } \\
\text { idade, tendo como base os dados } \\
\text { do lnep e IBGE. }\end{array}$ \\
\hline $\begin{array}{l}\text { Maria Aparecida } \\
\text { Camarano Martins }\end{array}$ & UNESCO & $\begin{array}{l}\text { GO, } E S, \\
C E, \quad M A, \\
P I, P A, A P, \\
M S, S C\end{array}$ & $31.000,00$ & $\begin{array}{l}\text { Consultoria especializada para } \\
\text { propor processos de planejamento } \\
\text { técnico-pedagógico e de gestão/ } \\
\text { avaliação da política de educação } \\
\text { infantil nos municípios participantes } \\
\text { do Proinfância, com vistas ao aprimo- } \\
\text { ramento das propostas pedagógicas } \\
\text { em congruência com as Diretrizes } \\
\text { Curriculares Nacionais para a } \\
\text { Educação Infantil - DCNEl. }\end{array}$ \\
\hline $\begin{array}{l}\text { Maria da Graça } \\
\text { Horn }\end{array}$ & UNESCO & $(*)$ & $30.000,00$ & $\begin{array}{l}\text { Realizar estudos e proposições de or- } \\
\text { ganização do funcionamento do uso } \\
\text { dos espaços físicos do Proinfância. }\end{array}$ \\
\hline
\end{tabular}




\section{Quadro 2}

Mapa dos Estados atendidos pelas consultorias (BRASIL, 2014) (Continuação)

\begin{tabular}{|c|c|c|c|c|}
\hline$\underset{\text { consultor }}{\text { Nome }}$ do & $\begin{array}{l}\text { Orga n is mo } \\
\text { Internacional }\end{array}$ & Estados & Recurso & Objeto do contrato \\
\hline $\begin{array}{l}\text { Mirella Villa de } \\
\text { AraujoTucunduva } \\
\text { da Fonseca }\end{array}$ & UNESCO & $\begin{array}{l}\text { GO, ES, } \\
C E, \quad M A, \\
P I, P A, A P, \\
M S, S C\end{array}$ & $31.000,00$ & \multirow{3}{*}{$\begin{array}{l}\text { Consultoria especializada para } \\
\text { propor processos de planejamento } \\
\text { técnico-pedagógico e de gestão/ } \\
\text { avaliação da política de educação } \\
\text { infantil nos municípios participantes } \\
\text { do Proinfância, com vistas ao aprimo- } \\
\text { ramento das propostas pedagógicas } \\
\text { em congruência com as Diretrizes } \\
\text { Curriculares Nacionais para a } \\
\text { Educação Infantil-DCNEl. }\end{array}$} \\
\hline $\begin{array}{l}\text { Sonia Maria de } \\
\text { Melo Barbosa }\end{array}$ & UNESCO & $\begin{array}{l}G O, \quad E S, \\
C E, \quad M A, \\
P I, P A, A P, \\
M S, S C .\end{array}$ & $31.000,00$ & \\
\hline Valdete Coco & UNESCO & $\begin{array}{l}\text { GO, ES, } \\
C E, \quad M A, \\
P I, P A, A P, \\
M S, S C .\end{array}$ & $60.000,00$ & \\
\hline TOTAL & & & $447.000,00$ & \\
\hline
\end{tabular}

${ }^{*}$ ) Não consta o local em que prestou consultoria - legenda produzida pela autora (2017). Fonte: Brasil (2014).

Observa-se (quadro 2) que as consultorias de 2013 buscaram concluir o trabalho de atendimento aos estados que ficaram desassistidos em 2012. Entretanto, observa-se que São Paulo e Minas Gerais não foram atendidos. Partindo de um princípio de universalização das políticas educacionais, todo o território brasileiro deveria ser contemplado. Por outro lado, a exclusão de um ou outro estado segue a perspectiva da focalização, por exemplo, por motivos econômicos, políticos ou geográficos.

A influência das consultorias decorre da intervenção que provocam nas organizações, posturas praticadas e ferramentas implementadas com a cultura da gestão. Nesse tipo de trabalho, parece ter se proliferado a padronização das soluções ligadas à gestão que são repassadas às organizações. Num estudo de 2013, realizado com a consultoria McKinsey \& Company, foi constatado que a referida empresa apresentava aproximadamente 400 projetosvoltados para a educação, espalhados por 60 países. Tais projetos são 
voltados para construção de ações duradouras voltadas a melhores resultados e índices obtidos pelos alunos, bem como para desenvolver a qualidade da educação (PERONI, 2013). Seguindo essa mesma lógica, o MEC contratou esse serviço por meio de convênio com organismos internacionais.

A esfera pública busca oferecer serviços à população com o objetivo de atender aos preceitos constitucionais. Na procura pelo equilíbrio dos gastos públicos, o Estado busca o superávit entre o valor arrecadado e as despesas realizadas para otimizar a sua gestão em prol de seus propósitos. De modo geral, a concepção que permeia o espaço governamental tem se fundamentado no princípio de que a redução dos gastos não resulta em prejuízo na qualidade dos serviços prestados (RIBEIRO, 2008). Os órgãos governamentais, responsáveis pela gestão do recurso público destinado à educação, se alinham com tais princípios, sugerindo o corte nos gastos em seus relatórios.

Aqui, as políticas públicas são entendidas a partir da conceituação de Höfling (200 1), que as define como o Estado em ação, implantando um projeto de governo, através de ações voltadas para setores específicos da sociedade. Conforme verificado até aqui, as políticas públicas educacionais e sociais têm sido destinadas a garantir às populações mais pobres um mínimo de serviços 18 de primeira necessidade, o caráter focalizado justifica-se pela necessidade de combate à pobreza. Entretanto, a política focalizada possui caráter paliativo e compensatório e caminha na contramão da política universal.Elas são específicas de um tipo particular de Estado, constituem-se como formas de interferência do Estado, visando à manutenção das relações sociais de determinada formação social (HÖFLING, 2001). Em verdade, buscam conter astensões ocasionadas pela concentração da riqueza.

A contratação de consultorias executadas no âmbito do Proinfância evidencia as ações focalizadas, bem comouma preocupação do Estado com a lógica da redução de gastos. Nessa perspectiva, entendemos que o Estado nega a todas as crianças o direito à educação infantil de qualidade.

Ao analisar as recomendações para o financiamento e gestão da educação básica no Brasil, recorremos ao estudo de Moreira (2012) que evidencia as categorias políticas recorrentes nos documentos dos organismos internacionais com atuação no Brasil. Conforme o estudo, a categoria otimização dos gastos, que consiste em recomendações pautadas na redução dos gastos com educação ou na alocação dos recursos, encontra-se evidenciada nos 
Dulce Mara Langhinotti Carpes | Ângela Mara de Barros Lara

documentos da Unesco, OCDE e Banco Mundial. A Racionalização de despesas, consta nos documentos da Unesco, já o Banco Mundial utiliza o termo Melhoria do clima de investimento. A Focalização no combate à pobreza é tratada nos documentos da OCDE e do Banco Mundial. A Parceria por meio da Cooperação Internacional, as novas alianças na captação de recursos com setor privado são recorrentes nos documentos da Unesco e da OCDE. O termo Equidade é recorrente nos documentos do Banco Mundial, OCDE, Unesco. $O$ termo descentralização ou financiamento flexível aparece nos documentos da Unesco (MOREIRA, 2012).

Da recorrência das categorias nos documentos verificadas no estudo de Moreira (2012), pode-se extrair que os organismos internacionais coadunam entre si, atuando com concepções, estratégias e objetivos comuns. As análises dos relatórios de gestão 2012 e 2013 nos indicam que as políticas educacionais brasileiras estão orientadas e espelham uma forma de gestão pública pautada pela pouca utilização de recursos. Portanto, os recursos destinados à educação infantil no Brasil estão inseridos no contexto de se fazer mais com menos.

\section{Considerações finais}

O estudo objetivou analisar como se viabilizaram os recursos públicos destinados à implementação da política nacional para educação infantil por intermédio de convênios firmados pelo Brasil com os organismos internacionais para contratação de consultorias no período de 2012 e 2013 . É possível arguir que os convênios com os parceiros externos OEI e UNESCO, firmados para contratação de consultorias, representam o consentimento para interferência externa nos caminhos seguidos pelo MEC na elaboração de suas políiticas.

De modo geral, as consultorias tiveram como foco implantação e aprimoramento das propostas pedagógicas alinhadas com as DCNEl nos municípios participantes do Proinfância. Porém, no ano de 2012, ao condicionar o apoio a esses municípios, demonstram que as propostas pedagógicasforam realizadas na lógica da focalização. Nesse sentido, o MEC se contradiz quando propõe a universalidade das políticas, por não ser factível garantir políticas universais viabilizando políticas focalizadas. 
As consultorias em 2013 concluem o trabalho de atendimento aos estados que ficaram desassistidos em 2012. Entretanto, observa-se que São Paulo e Minas Gerais não foram atendidos, seguindo a mesma lógica da focalização e políticas pontuais para diminuir pobreza, como consta nos documentos do Banco Mundial.Partindo do princípio de que um dos maiores objetivos do Banco Mundial, discutido nas conferências mundiais, se configura na sustentabilidade e sociabilidade do sistema capitalista, deduz-se que o Brasil estaria alinhando suas políticas no campo educacional às diretrizes dos organismos internacionais.

Nessa linha de raciocínio, verificamos que o modelo educacional brasileiro está pautado na lógica utilitarista e determinista, uma vez que as políticas são orientadas para oferecer aos trabalhadores condições básicas de conhecimento, para que, minimamente, operacionalizem funções simplificadas.

Os recursos financeiros destinados às consultorias não têm representatividade significativa no montante geral de recursos investidos na educação infantil, nos anos de 2012 e 2013 (INEP, 2015). Entretanto, entendemos haver um custo nessa relação, tendo em vista que o Estado brasileiro acata as intervenções externas na construção e execução de políticas educacionais. 20 Entendemos que deveria ser o MEC o órgão responsável pela elaboração e condução das políticas educacionais no país, de modo que os educadores fossem os atores principais nesse pro-cesso.

Não foi possível verificar a efetividade do trabalho realizado pelas consultorias na análise do conteúdo. Outrossim, identificamos o montante de recursos investidos na contratação, as empresas contratadas, a proposição de ações de cada consultoria e a área geográfica de atua-ção. A equipe contratada era constituída por intelectuais e ex-integrantes da Equipe COEDI/MEC. De modo geral, os serviços contratados tiveram caráter propositivo, contendo subsídios para o desenvolvimento da qualidade da educação infantil. Outro ponto identificado, e que se constitui numa prática frequente das consultorias, refere-se aos procedimentos generalizantes de gestão apontadospelos consultores. Destarte, nem sempre adequada à realidade dos países periféricos que têm suas especificidades alijadas.

De modo geral, as consultorias contratadas pelo MEC responderam positivamente aos objetivos de uma agenda globalmente estruturada, na qual a OEl e a UNESCO atuam no sentido de salvaguardar o interesse dos organismos 
financiadores, além de disseminá-lo nos países periféricos para que cumpram metas estipuladas. Percebe-se que a destinação dos recursos públicos para educação no Brasil segue a lógica da racionalização dos gastos, o que entendemos não contribuir a favor da garantia do direito que cada criança possui de uma formação humana ampla, universal e inalienável, desde os primeiros meses de idade, conforme prevê a lei.

Nota-se que aspectos quantitativos têm prevalecido em detrimento dos qualitativos, portanto, não se visualiza perspectivas de desenvolvimento na qualidade da educação quando esta é entendida como um gasto. A adoção de uma gestão pautada na redução de um recurso já insuficiente resulta em prejuízo na qualidade dos serviços prestados, o que leva à precarização da educação.

\section{Notas}

1 Como Campos e Campos (2008) e Campos (2013).

2 Tem sido vista como forma de redução dos custos e alternativas de otimização dos recursos materiais e humanos (LINS, 1999).

3 Documento com o receituário para ser aplicado nos países endividados da periferia do sistema capitalista (FRIGOTTO, 2015).

4 Ministério da Reforma do Estado.

5 Cultura da Gestão refere-se à filosofia de gestão promovida por reformas no setor público, utilizada pelos governos após a década de 1980 para a modernização dos setores (PERONI, 20131.

6 Países da América ligados aos impérios coloniais português e espanhol.

7 O documento Objetivos de Desenvolvimento do Milênio - ODM trouxe alcançar a educação básica de qualidade para todos como meta principal.

8 Programa Nacional de Reestruturação e Aquisição de Equipamentos para a Rede Escolar Pública de Educação Infantil, criado em 2007.

\section{Referências}

BANCO MUNDIAL. Relatório sobre o desenvolvimento mundial 1990: à pobreza. Washington, DC: Oxford University Press, 1990.

BARDIN, Laurence. Análise de conteúdo. Lisboa: Edições 70, 1977. 
BRASIL. Constituição da República Federativa do Brasil. São Paulo: Imprensa Oficial do Estado, 1988.

BRASIL. Lei n 9.394, de 20 de dezembro de 1996. Estabelece as Diretrizes e as Bases da Educação Nacional. Diário Oficial [da União], Poder Executivo, Brasília, DF, 23 de dezembro de 1996.

BRASIL.Ministério da Educação. Secretaria de Educação Básica. Relatório de Gestão 2012. Brasília: MEC/SEB, 2013.

BRASIL. Ministério da Educação. Secretaria de Educação Básica. Relatório de Gestão 2013. Brasília: MEC/SEB, 2014.

CAMPOS, Rosânia. A educação infantil e os organismos internacionais: quando focalizar não é priorizar. Education Policy Analysis Archives, Arizona, EUA, v. 21, n. 18, p. 1-16, mar. 2013.

CAMPOS, Rosânia; CAMPOS, Roselane Fátima. A educação das crianças pequenas como estratégia para o alívio da pobreza. Revista InterAção, Goiania, v. 33, n. 2, p. 24 1-263, jul./dez. 2008.

CEPAL. Comisión Económica para América Latina y el Caribe. CEPAL y Organización de las Naciones Unidas para la Educación, la Ciencia y la Cultura (UNESCO). Santiago: Serie 22 Seminarios y Conferencias, 2005.

EVANGELISTA, Olinda. Apontamentos para o trabalho com documentos de política educacional. In: ARAÚJO, Ronaldo Marcos de Lima; RODRI-GUES, Doriedson S. (Org.). A pesquisa em trabalho, educação e políticas educacionais. Campinas: Alínea, 2012.

EVANGELISTA, Olinda; SHIROMA, E. O. Educação para alívio da pobreza: novo tópico na agenda global. Revista de Educação PUC-Campinas, Campinas, v. 20, p. 43-54, jun. 2006.

FONTES, Virgínia. O Brasil e o capital-imperialismo: teoria e história. Rio de Janeiro: Editora UFRJ, 2010.

FERNANDES, Silvia Reis. Concepções e práticas de avaliação vigentes em escolas públicas: a influência das políticas educacionais no trabalho dos professores. 2015. 129 f. Dissertação (Mestrado em Educação) - PUC/Goiás, Goiânia, 2015.

FRIGOTTO, Gaudêncio; CIAVATTA, Maria. Educação básica no Brasil na década de 1990: subordinação ativa e consentida à lógica de merca-do. Educação \& Sociedade, Campinas, v. 24, n. 82, p. 93-130, abr. 2003.

FRIGOTTO, Gaudêncio. A produtividade da escola Improdutiva 30 anos depois: regressão social e hegemonia às avessas. Trabalho Necessário, Rio de Janeiro, n. 20, ano 
13, p. 206-233, 2015. Disponível em: http://www.uff.br/trabalhonecessario/images/ TN_20/10_frigotto.pdf. Acesso em: 20 nov. 2016.

GORENDER, Jacob. Globalização, tecnologia e relações de trabalho. Estudos Avançados, São Paulo, v. 11 , n. 29, p. 31 1-361, jan./abr. 1997.

HÖFlING, Eloisa de Mattos. Estado e políticas (públicas) sociais. Caderno CEDES, Campinas, v. 21 , n. 55, p. 30-41, nov. 2001.

INEP. Instituto Nacional de Pesquisas Educacionais Anísio Teixeira. Investimentos Públicos em Educação, 20 de outubro de 2015. Disponível em: http://portal.inep.gov.br/investimentos-publicos-em-educacao. Acesso em: 15 fev. 2017.

LEHER, Roberto. Da ideologia do desenvolvimento à ideologia da globalização: a educação como estratégia do Banco Mundial para "alívio" da pobreza. 1998. 266 f. Tese (Doutorado em Educação) - Programa de Pós-Graduação em Educação, Universidade de São Paulo, São Paulo, 1998.

LIBÂNEO, José Carlos. O dualismo perverso da escola pública brasileira: escola do conhecimento para os ricos, escola do acolhimento social para os pobres. Educação e Pesquisa, São Paulo, v. 38, n. 1, p. 13-28, mar. 2012.

LIBÂNEO, José Carlos. Políticas educacionais no Brasil: desfiguramento da escola e do conhecimento escolar. Cadernos de Pesquisa, São Paulo, v. 46, n. 159, p. 38-62, jan./ mar. 2016.

LINS, Nadja Vanessa Miranda. Consultoria: um novo enfoque em aplicação de jogos de empresas. 1999. 94 f. Dissertação (Mestrado em Engenharia da Produção) - Programa de Pós-Graduação em Engenharia de Produção, Universidade Federal de Santa Catarina, Florianópolis, 1999.

MIRANDA, Marília G. de; SANTOS, Soraya V. Propostas de tempo integral: a que se destina a ampliação do tempo escolar? Perspectiva, Florianópolis, v. 30, n. 3, p. 1073-1098, set./dez. 2012.

MOREIRA, Jani Alves da Silva. Políticas de financiamento e gestão da educação básica ( 1990-20 10): os casos Brasil e Portugal. 2012. 357 f. Tese (Doutorado em Educação) Programa de Pós-Graduação em Educação, Universidade Estadual de Maringá, Maringá, 2012.

PAULO NETTO, José. As condições histórico-sociais da emergência do serviço social. In: PAULO NETTO, José. Capitalismo monopolista e serviço social. São Paulo: Cortez, 2006.

NEVES, Lúcia Maria Wanderley. A nova pedagogia da hegemomia: estratégias do capital para educar o consenso. São Paulo: Editora Xamã, 2005. 
OEl. Organização dos Estados Ibero-americanos para a Educação, a Ciência e a Cultura. Declaración de Panamá: La Educación Inicial en el Siglo XXI. X Conferencia lberoamericana de Educación. Ciudad de Panamá, Panamá, jul. 2000.

OEl. Organização dos Estados Ibero-americanos para a Educação, a Ciência e a Cultura. Declaración de Lima: "Agenda Iberoamerica para la niñez e la adolescência". CONFERENCIA IBERO-AMERICANA DE MINIS-TRAS, MINISTROS Y ALTOS RESPONSABLES DE LA INFANCIA Y ADOLES-CENCIA, 3, 2001, Lima. Anais [...]. Lima (Perú), 2001.

OEl. Organização dos Estados Ibero-americanos para a Educação, a Ciência e a Cultura. Fuentes de financiamiento adicionales para lograr el compromiso con las metas educativas 2021 . In: OEI. Metas 2021: La educación que queremos para la generación de los bicentenarios. Síntesis del debate. Madri, Espanha: OlE, 2008.

PEDREIRA, Roberto Sampaio. O relacionamento Brasil-Banco Mundial: uma análise da dimensão política e econômica (1985-2005). 2006. 189 f. Dissertação (Mestrado em Ciência Política) - Programa de Pós-Graduação em Ciência Política, Universidade de Brasília, Brasília, 2006.

PERONI, Vera María Vidal. Redefinições das fronteiras entre o público e o privado: implicações para a democratização da educação. Brasília: Liber Livro, 2013.

RIBEIRO, Márcio Bruno. Desempenho e eficiência do gasto público: uma análise comparativa entre o Brasil e um conjunto de países da América Latina. Rio de Janeiro: IPEA, 2008.

SILVA, Maria Abádiada. Dimensões da política do Banco Mundial para a educação básica pública. In: SILVA, Maria Abádiada; CUNHA, Celso da (Org.). Educação básica: políticas, avanços e pendências. Campinas: Autores Associados, 2014.

UNESCO. Declaração Mundial sobre Educação para Todos: Plano de Ação para satisfazer as necessidades básicas de aprendizagem aprovada pela Conferência mundial sobre Educação para todos: satisfação das necessidades básicas de aprendizagem. Jomtien, Tailândia, 5 a 9 de março de 1990. Brasília, DF: UNESCO, 1990.

ZANARDINI, Isaura Mônica Souza. A ideologia da pós-modernidade e a política de gestão educacional brasileira. 2006. 173 f. Tese (Doutorado em Educação) - Programa de Pós-Graduação em Educação, Universidade Estadual de Campinas, Campinas, 2006.

ZANARDINI, João. Políticas de avaliação da educação pública. In: SANTOS, Alex S. B. dos; EVANGELISTA, Olinda. Políticas para a educação básica no Brasil. Florianópolis: NUP/Sintrasen, 2014. 
Ms. Dulce Mara Langhinotti Carpes Doutoranda do Programa de Pós-Graduação em Educação Universidade Estadual de Ponta Grossa (Paraná - Brasil) Professora da Secretaria de Estado da Educação do Estado do Paraná Grupo de Estudos e Pesquisas em Estado, Políticas Educacionais e Infância (GEPPEIN) ORCID ID: https: / / orcid.org/0000-0003-3013-063

E-mail: dulcelanghinotti@gmail.com Profa. PhD. Ângela Mara de Barros Lara Professora Colaboradora doPrograma de Pós-Graduação em Educa-ção Universidade Estadual de Maringá (Paraná - Brasil) Grupo de Estudos e Pesquisas em Estado, Políticas Educacionais e Infância (GEPPEIN) ORCID ID: http:/ / orcid.org/0000-000 1-8799-8413 E-mail: angelalara@ymail.com

Recebido 5 maio 2019 Aceito 7 jun. 2019 